\title{
Noise Reduction Effect of Low Barriers Installed Adjacent to Rails
}

\author{
Yukie OGATA \\ Senior Researcher, \\ Kiyoshi NAGAKURA, Dr. Eng. \\ Noise Analysis Laboratory, Environmental Engineering Division
}

\begin{abstract}
Recently, complaints regarding railway noise have increased from residents living in high-rise buildings facing railway tracks. However, reducing noise for locations high above the tracks with conventional noise barriers is difficult, because the noise sources are directly visible from these elevated positions. This paper investigated the effect on noise of low barriers installed adjacent to rails. It was evident through acoustic tests using scale models and field tests on existing railways that this type of noise barrier is able to reduce noise even in locations high above the track. Furthermore, a prediction model of the effect of these noise barriers was proposed based on the results of the field tests.
\end{abstract}

Keywords: noise barriers, railway noise, elevated positions

\section{Introduction}

Noise generated from each railway sound source propagates to the wayside. Noise from the under-body of vehicles is particularly powerful and has many sources, which means it has a great influence on wayside noise generated on both Shinkansen and conventional lines. Consequently, it is necessary to identify effective countermeasures against this type of noise. Wayside noise is generally evaluated as sound measured at a distance of $1.2 \mathrm{~m}$ from ground level according to the Environmental Quality Standards for Shinkansen Superexpress Railway Noise or the Guidelines for Noise Abatement Measures in the Construction of New Lines and Largescale Improvement of Conventional Railways in Japan. For this reason, countermeasures to date have focused mainly on abating this type of wayside noise, for example installation of noise barriers along the edge of bridges or railway sites. Reducing noise in elevated positions facing the tracks with the same conventional noise barriers, however, is difficult, because noise sources at the under-body of vehicles are directly visible from the high-rise buildings in question.

In this paper, low barriers were installed adjacent to rails to act as countermeasures to noise propagation in high locations, and their noise reduction effect was investigated. It was found through acoustic tests using scale models and field tests on actual tracks [1] that this type of noise barrier was capable of reducing noise in elevated positions. The installation conditions of the low barriers were varied for the tests. The adjustable low barrier parameters were height, shape and presence of absorbers. Furthermore, a model to predict the noise reduction effect of these low barriers on the noise generated from the under-body of vehicles was proposed based on the results of the field tests.

\section{The effect of low barriers installed adjacent to rails observed through acoustic tests}

\subsection{Summary of the acoustic tests with scale models}

In order to examine the noise reduction effect on wayside noise of low barriers installed adjacent to the rails, acoustic tests were conducted with scale models in an anechoic room in RTRI. The scale models of cars, tracks and railway structures, sound sources and microphone were installed in the room; they were used to simulate an electric multiple unit running on conventional line. The parameters of the low barriers for the tests were distance from rail, height, shape and presence of absorbers. The acoustic absorption properties of the sound absorbers were equivalent to those of glass wool. Both flat-wall type and inverted $\mathrm{L}+\mathrm{T}$ type (flat wall with a horizontal overhanging ledge which is a board fixed to the top edge of the barriers) low barriers were employed. Measurements were taken by using a single microphone placed at 64 points in a plane perpendicular to track. The summary of the tests is as follows:

(1) Test place: anechoic room in RTRI

(2) Scale model: 1/20 scale, double track on concrete bridge for a conventional line, with or without conventional barriers (flat, without sound absorbers, $2 \mathrm{~m}$ high from R.L.), slab track (reflective), 3 cars (equivalent length of $60 \mathrm{~m}$ )

(3) Noise sources: line omni-directional sound sources using air jet, located under cars to simulate noise generated by the under-body of vehicles,

(4) Shape of the barriers (Fig. 1): inverted L + T type, flat type- A, flat type- B, $0.5 \mathrm{~m}$ or $0.9 \mathrm{~m}$ high from R.L., sound absorbers: with or without $5 \mathrm{~mm}$ thick spongiform porous material [2] inside the flat section,

(5) Measurement (Fig. 2): using a 1/4 inch single microphone (UC-29), distance from near track-center of 0 $25 \mathrm{~m}$ (horizontal direction) and distance from R.L. of -5 - +20 m (vertical direction).

(6) Analysis method: the data measured with the microphone were analyzed by FFT, and summed up to $1 / 3$ octave band frequency components. By applying the acoustic similarity law, the frequency obtained was multiplied by $1 / 20$. The difference in sound pressure level for each $1 / 3$ octave band frequency between results obtained in the scaled model tests and field tests (electric multiple unit running at $80 \mathrm{~km} / \mathrm{h}$ on conventional line) was estimated by comparing the results with those measured at a reference point (distance from near track-center of $2 \mathrm{~m}$, height from R.L. of 0.45 $\mathrm{m})$ as shown in Fig. 3. The difference was then added 


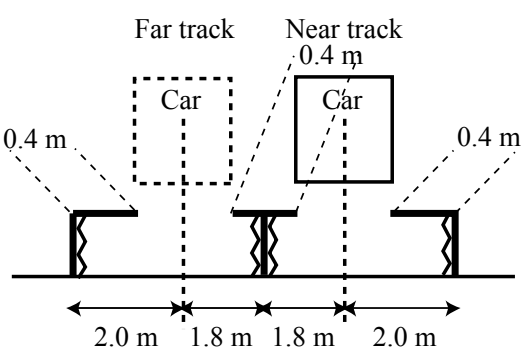

(a) Inverted L $+\mathrm{T}$ type

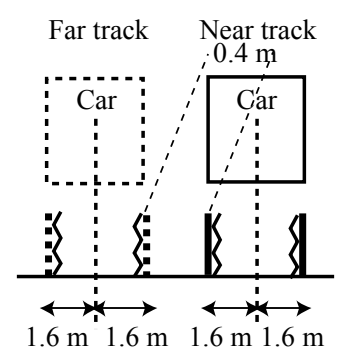

(b) Flat type-A

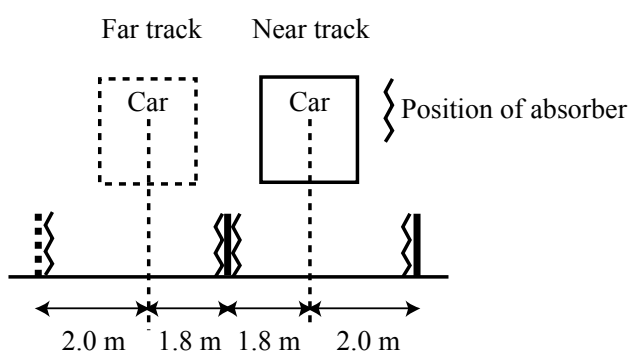

(c) Flat type-B

Fig. 1 Conditions of low barriers installed adjacent to rails

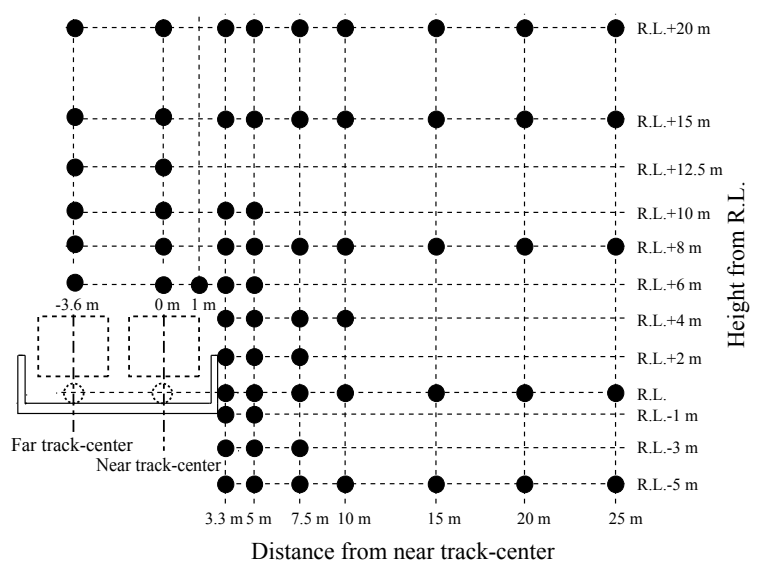

Fig. 2 Measuring points (Scale shown in full-scale)

to the results obtained at various points in the acoustic test in the form of an absolute spectrum, and the overall levels were calculated by summing up all the frequency components.

\subsection{Results of the acoustic tests with scale models}

This section describes results obtained with conventional barrier conditions. Fig. 4 shows the distribution of wayside noise without low barriers installed adjacent to the rails and with the conventional barriers (without absorbers). This figure shows that the sound pressure level suddenly falls in regions below the virtual straight line linking the sound source to the upper edge of the conventional barrier. The noise reduction effect in the area below R.L. therefore is sufficient with the conventional barriers. In this zone, the noise from a train on the near track is lower than the noise from a train on the far track. On the other hand, the noise generated from the under-body of vehicles propagates strongly upward and the sound pressure level in higher locations is much greater than in the region below R.L.. Therefore, it is understood that noise reduction in elevated positions by using only conventional barriers is difficult. Figure 5 shows the difference in wayside noise between the model conditions shown in Fig. 4 and those for where low barrier with absorbers have been install adjacent to the rails. It is found that wayside noise decreases in the whole region when low barriers with absorbers were installed, especially in the upper region where the noise otherwise propagated strongly.

Estimation of the sound pressure level at typical el-

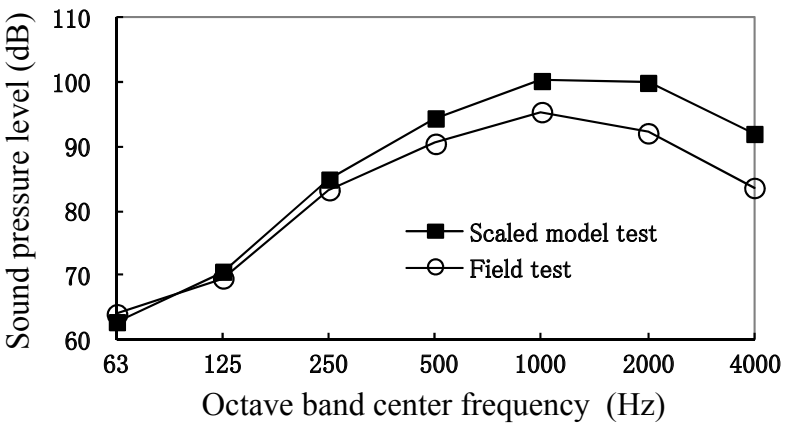

Fig. 3 Characteristic of noise spectrum at the reference point near the rails (Electric multiple unit running at $80 \mathrm{~km} / \mathrm{h}$ )

evated points (distance from near track-center of $12.5 \mathrm{~m}$, height from R.L. of $10 \mathrm{~m}$ or $20 \mathrm{~m}$ ) are shown for each set of conditions with low barriers in Table 1 . The main results obtained from Fig. 4, Fig. 5, and Table 1 can be summarized as follows:

(1) If no low barriers are installed adjacent to the rails, the wayside noise from passing trains on the near track is smaller than wayside noise from a passing train on the far track. On the other hand, if low barriers are installed adjacent to the rails, the reverse is true, i.e. noise on the far track from passing trains is greater than on the near side track.

(2) If there are no absorbers, the wayside noise with the flat type-A barriers is lower than with the flat type-B barriers. As the distance from the low barriers to the noise source is shorter, the noise reduction effect of the low barriers increases.

(3) For low barriers of the same height installed adjacent to the rails with no absorbers, inverted $\mathrm{L}+\mathrm{T}$ type barriers are the most effective for reducing noise of all the barriers for all conditions except where in special positions.

(4) If there are absorbers on barriers, where the height of low barriers is $0.5 \mathrm{~m}$, wayside noise is somewhat lower with inverted $\mathrm{L}+\mathrm{T}$ type barriers than with the flat type-A barriers. However, where the height is 0.9 $\mathrm{m}$, the opposite is true. Where barrier height is $0.9 \mathrm{~m}$, noise reduction at a distance of $12.5 \mathrm{~m}$ from the near track-center and height $20 \mathrm{~m}$ above R.L. with the flat type- A barriers is $6.5 \mathrm{~dB}$, whereas with inverted $\mathrm{L}+\mathrm{T}$ type barriers it is $5.5 \mathrm{~dB}$. The noise reducing impact of absorbers at the typical points is about $1-4 \mathrm{~dB}$. 


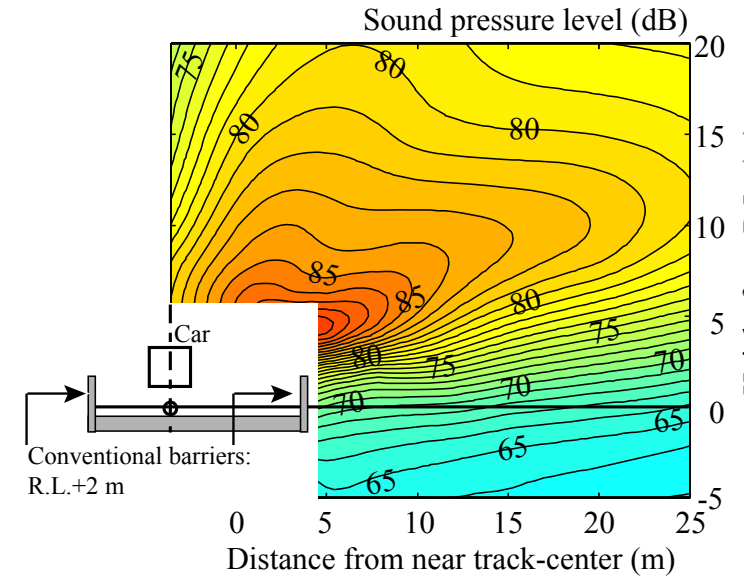

(a) Far track

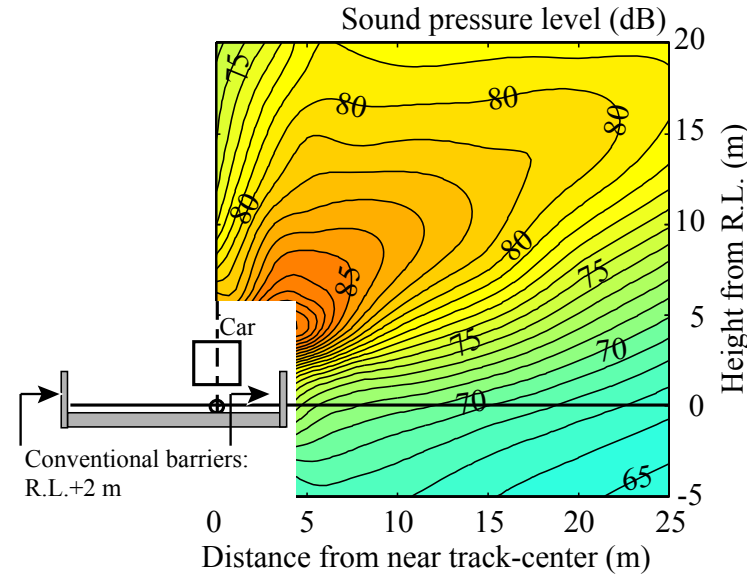

(b) Near track

Fig. 4 Noise distribution in the acoustic tests with only conventional barriers

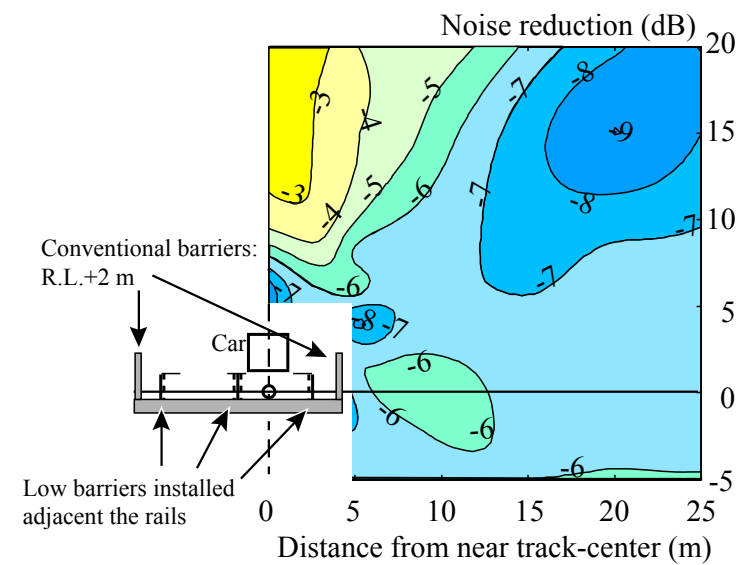

(a) Near track,

Inverted $\mathrm{L}+\mathrm{T}$ type barriers equipped with absorbers

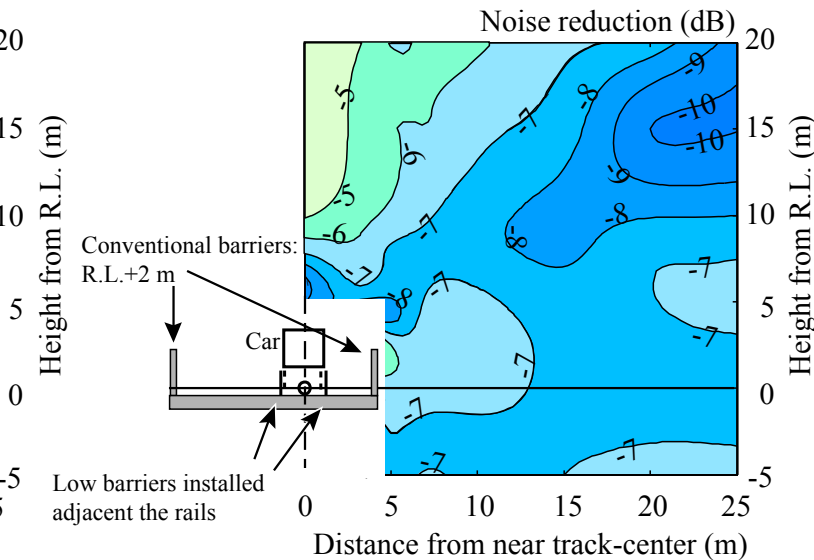

(b) Near track,

Flat type-A barriers equipped with absorbers

Fig. 5 Noise reduction of low barriers installed adjacent to rails

(These figures show noise levels for cases with conventional barriers and low barriers minus the noise level for cases with only conventional barriers.)

Table 1 Predicted noise levels at typical points in the acoustic tests (with conventional barriers, Distance from the near track-center is $\mathbf{1 2 . 5} \mathrm{m}$ )

\begin{tabular}{|c|c|c|c|c|c|}
\hline \multirow{3}{*}{\multicolumn{2}{|c|}{ Low barrier conditions }} & \multirow{2}{*}{\multicolumn{2}{|c|}{$\frac{\text { Car on near track }}{\text { Measuring position }}$}} & \multirow{2}{*}{\multicolumn{2}{|c|}{$\frac{\text { Car on far track }}{\text { Measuring position }}$}} \\
\hline & & & & & \\
\hline & & \multirow{2}{*}{$\frac{\text { R.L. }+10 \mathrm{~m}}{81.8}$} & \multirow{2}{*}{$\begin{array}{c}\text { R.L. }+20 \mathrm{~m} \\
77.7\end{array}$} & \multirow{2}{*}{$\begin{array}{c}\text { R.L. }+10 \mathrm{~m} \\
81.0\end{array}$} & \multirow{2}{*}{$\begin{array}{c}\text { R.L. }+20 \mathrm{~m} \\
76.9 \\
\end{array}$} \\
\hline Without & Flat type-A, $0.5 \mathrm{~m}$ high & & & & \\
\hline \multirow{5}{*}{ absorbers } & Flat type-B, $0.5 \mathrm{~m}$ high & 82.6 & 78.5 & 81.0 & 77.1 \\
\hline & Inverted $\mathrm{L}+\mathrm{T}$ type, $0.5 \mathrm{~m}$ high & 81.3 & 77.6 & 80.4 & 75.9 \\
\hline & Flat type-A, $0.9 \mathrm{~m}$ high & 77.4 & 75.9 & 77.1 & 75.2 \\
\hline & Flat type-B, $0.9 \mathrm{~m}$ high & 81.0 & 79.0 & 77.3 & 75.9 \\
\hline & Inverted $\mathrm{L}+\mathrm{T}$ type, $0.9 \mathrm{~m}$ high & 77.9 & 75.4 & 76.0 & 74.2 \\
\hline \multirow{4}{*}{$\begin{array}{l}\text { With } \\
\text { absorbers }\end{array}$} & Flat type-A, $0.5 \mathrm{~m}$ high & 80.0 & 75.9 & & \\
\hline & Inverted $\mathrm{L}+\mathrm{T}$ type, $0.5 \mathrm{~m}$ high & 80.0 & 75.2 & 78.5 & 74.5 \\
\hline & Flat type-A, $0.9 \mathrm{~m}$ high & 74.5 & 72.2 & & \\
\hline & Inverted $\mathrm{L}+\mathrm{T}$ type, $0.9 \mathrm{~m}$ high & 75.5 & 73.2 & 71.7 & 70.2 \\
\hline & Without low barriers & 82.6 & 78.7 & 83.2 & 79.0 \\
\hline
\end{tabular}


3. The effect of low barriers installed adjacent to the rails in field tests

\subsection{Summary of the field tests}

In order to examine the effect of low barriers installed adjacent to the rails on wayside noise, field measurements were conducted at the test line in RTRI. There were no conventional barriers in the field tests. Noise measurements were made with microphones located in a plane perpendicular to track. The low barriers installed adjacent to the rails were equivalent to the flat type-B barriers used in the scale model acoustic tests. The summary of the field tests are as follows:

(1) Test track: straight test line on ballast in RTRI without conventional barriers

(2) Test car: a diesel railway locomotive coasting at a speed of approximately $30 \mathrm{~km} / \mathrm{h}$

(3) Condition of low barriers installed adjacent to the rails (Table 2): $30 \mathrm{~m}$ of low barriers were installed. The distance from track-center to the barriers was approximately $2 \mathrm{~m}$. The material employed was $5.5 \mathrm{~mm}$ thick plywood lined with a $0.5 \mathrm{~mm}$ layer of lead. The absorption material used was $50 \mathrm{~mm}$ polyester fiber with sound characteristics equivalent to glass wool.

(4) Measuring points (Fig. 6): The measuring section was located at center of the low barriers of $30 \mathrm{~m}$. The measuring points were distributed at distance from trackcenter of up to $9.3 \mathrm{~m}$ and height from R.L. up to $5 \mathrm{~m}$. There were 13 measuring points.

(5) Analysis method: measured data was analyzed for Aweighted sound pressure levels with time weighting F. In the time histories of A-weighted sound pressure levels, the level peaks corresponding to each bogie were estimated.

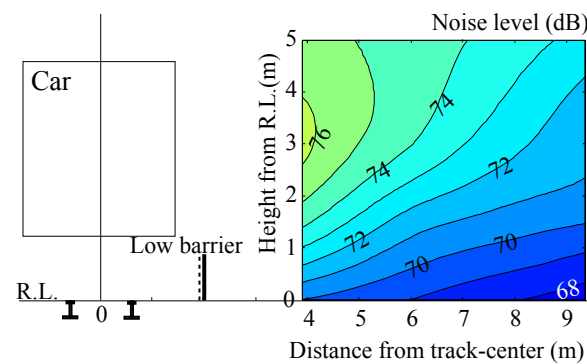

(a) Case 1 (Barriers $0.9 \mathrm{~m}$ high equipped with absorbers)

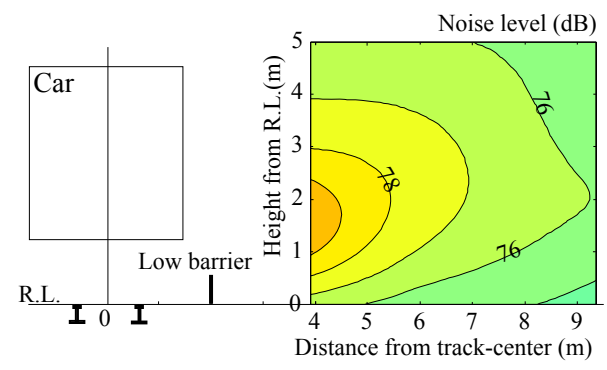

(c) Case 3 (Barriers $0.5 \mathrm{~m}$ high without absorbers)
Table 2 Installation conditions of low barriers adjacent to rails in the field tests

\begin{tabular}{|l|l|}
\hline Case 1 & $0.9 \mathrm{~m}$ above R.L., with absorbers \\
\hline Case 2 & $0.9 \mathrm{~m}$ above R.L., without absorbers \\
\hline Case 3 & $0.5 \mathrm{~m}$ above R.L., without absorbers \\
\hline Case 4 & Without low barriers \\
\hline
\end{tabular}

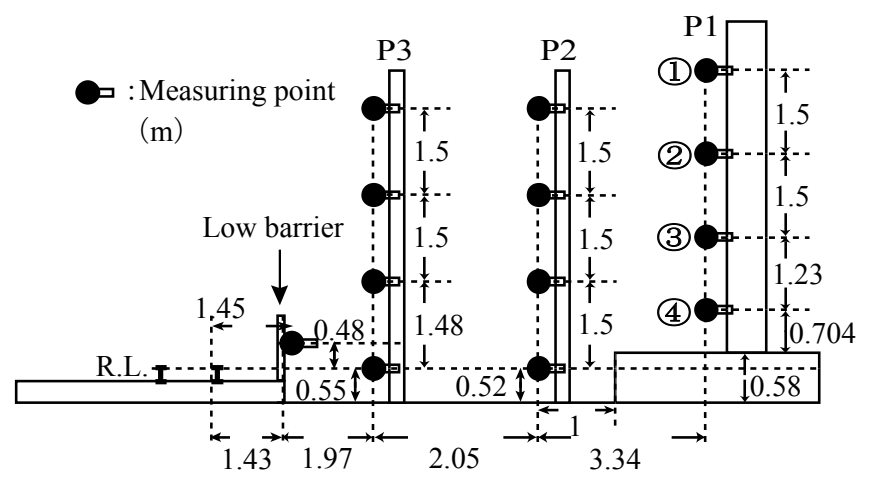

Fig. 6 Measuring points for the field tests

\subsection{Results of the field tests}

\subsubsection{Summary of the results}

The results of wayside noise measurements from the field tests are presented in Fig. 7. The figure shows that as the distance from the noise source to the measuring points grew, sound pressure level decreased where there were no low barriers. When low barriers were present, the sound pressure level behind the barriers decreased because of the shielding effect. The lower the barriers were, the lower the

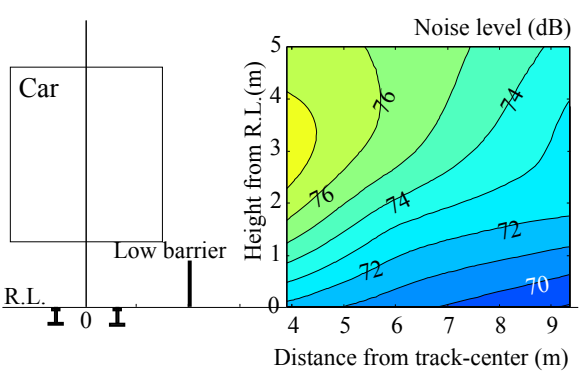

(b) Case 2 (Barriers $0.9 \mathrm{~m}$ high without absorbers)

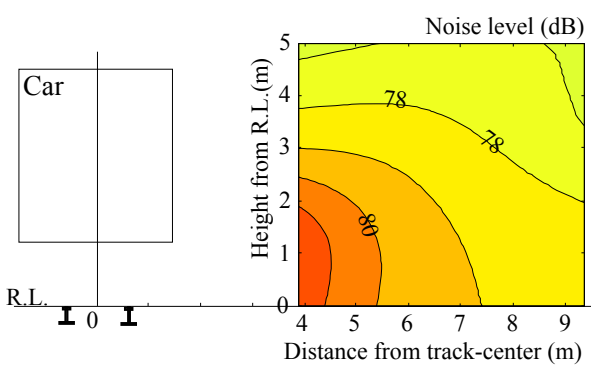

(d) Case 4 (Without barriers)

Fig. 7 Noise distribution in the field tests 
Table 3 Noise reduction in the acoustic and field tests (without conventional barriers, P1 (1): at a distance of $9.3 \mathrm{~m}, 5 \mathrm{~m}$ high)

\begin{tabular}{|c|c|c|}
\hline Case of low barriers & $\begin{array}{c}\text { Acoustic tests } \\
\text { (Flat type-B) }\end{array}$ & Field tests \\
\hline Case 1 & $8.2 \mathrm{~dB}$ & $4.3 \mathrm{~dB}$ \\
\hline Case 2 & $6.6 \mathrm{~dB}$ & $3.2 \mathrm{~dB}$ \\
\hline Case 3 & $2.7 \mathrm{~dB}$ & $1.5 \mathrm{~dB}$ \\
\hline
\end{tabular}

noise reduction effect became. The effect of absorbers was almost constant at a value of about $1.5 \mathrm{~dB}$ at all measuring points.

Table 3 shows noise reduction of the low barriers installed adjacent to the rails for the acoustic tests and the field tests. The position used for evaluation P1 (1) is shown in Fig. 6. In Table 3, noise reduction achieved with low barriers during the field tests was less than that in the acoustic tests. The reason why the shielding effect of low barriers in the field tests was lower than that in the acoustic tests is thought to be because noise sources in the acoustic tests were concentrated on the rail and the lower half of the wheel on the scale models whereas noise sources in the field tests with a diesel locomotive were spread throughout

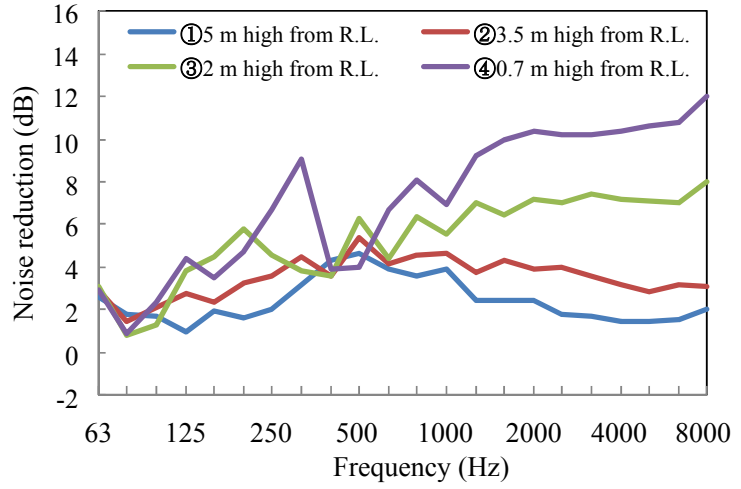

(a) Noise reduction in field tests (Barriers $0.9 \mathrm{~m}$ high, Case 2)

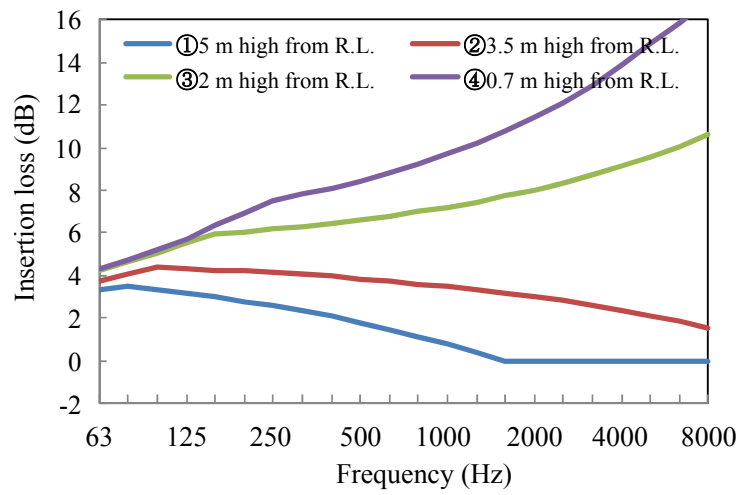

(c) Predicted insertion loss (Barriers $0.9 \mathrm{~m}$ high, Case 2) the whole of the bogie. Since the shielding effect of noise by low barriers varied greatly between measuring positions, noise distribution above the upper end of barriers was strongly affected by geometric size and position of the noise sources.

\subsubsection{Frequency characteristics of low barrier shielding effect}

Figures 8(a) and (b) show the frequency characteristics of noise reduction at four positions $9.3 \mathrm{~m}$ away from the track-center of low barriers installed adjacent to the rails in the field tests. In these figures, noise reduction at point P1 (4) (9.3 m away from the track-center and $0.7 \mathrm{~m}$ above R.L.) which was close to ground shows a peak in the $315 \mathrm{~Hz}$ band and a trough in the $500 \mathrm{~Hz}$ band. These local band frequency characteristics were due to the influence of interference of direct sound and reflected sound on the ground. Noise reduction at $2 \mathrm{~m}$ above R.L. for all bands tended to increase as frequency rose where barriers were $0.9 \mathrm{~m}$ above R.L. (Case 2). Where the measuring point was over $3.5 \mathrm{~m}$ above R.L., there was little difference in noise reduction between positions, and noise reduction was 0 $3 \mathrm{~dB}$. For where barriers were $0.5 \mathrm{~m}$ above R.L. (Case 3 ), there was little difference in frequency-dependent noise reduction except around the $100 \mathrm{~Hz}$ band. Noise reduction

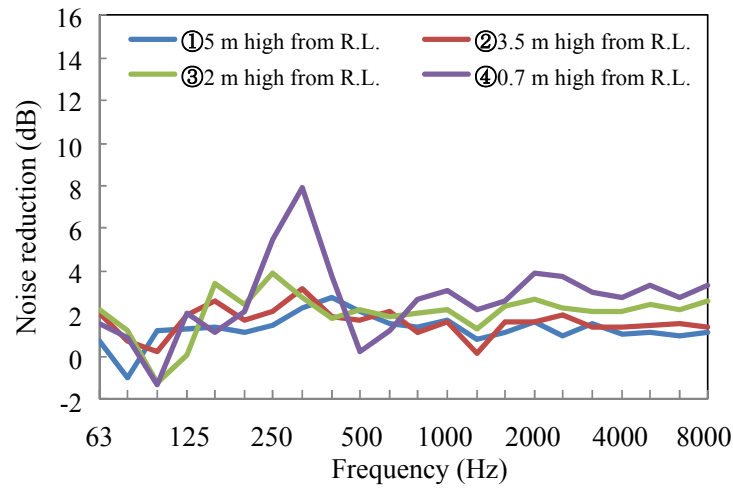

(b) Noise reduction in field tests (Barriers $0.5 \mathrm{~m}$ high, Case 3)

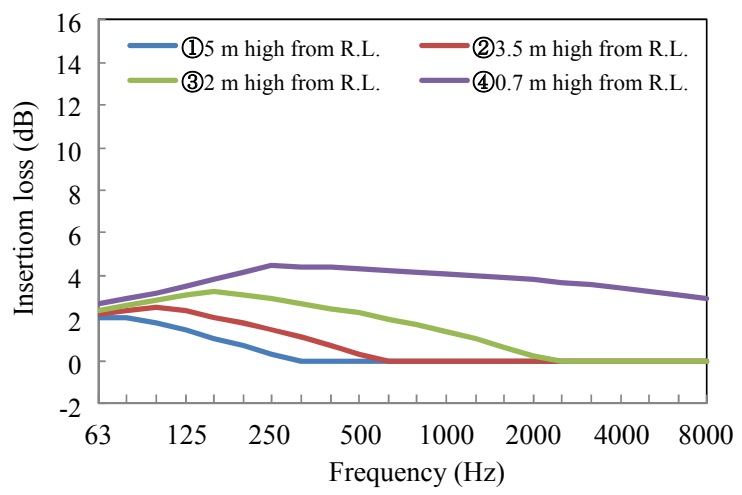

(d) Predicted insertion loss (Barriers $0.5 \mathrm{~m}$ high, Case 3)

Fig. 8 Comparison of noise direction in the field tests and predicted insertion loss of low barriers installed adjacent to the rails 
was approximately $1-3 \mathrm{~dB}$ in this case.

Figures 8(c) and (d) show the predicted insertion loss provided by low barriers installed adjacent to the rails. Insertion loss (source position: near the wheel, $0.5 \mathrm{~m}$ above R.L., evaluated points: $9.3 \mathrm{~m}$ away from the track-center) was calculated using the method applied to low barriers in the ASJ RTN-model for road traffic noise [3]. The influence of interference of direct sound and reflected sound on the ground were not taken into account. In these figures, the frequency characteristics of insertion loss in the case of positive path difference are different from where there was a negative path difference. Positive path difference signifies that the sources cannot be visible from the evaluated point and in the case of a negative path difference the opposite is true. Where the barriers are $0.9 \mathrm{~m}$ high, the evaluated points at $2 \mathrm{~m}$ and $0.7 \mathrm{~m}$ above R.L. have positive path differences whereas the other cases have a negative path difference. Where path difference was positive, insertion loss increased as frequency rose. When the path difference was negative, difference in frequency dependent insertion loss was lower with values of $0-4 \mathrm{~dB}$. As frequency is higher, the insertion loss for negative path difference will eventually converge to zero.

By comparing the noise reduction in the field tests (Fig. 8 (a) and (b)) and the predicted insertion loss shown in Fig. 8 (c) and (d), it is found that both the values tend to increase as the frequency rises, if the path difference is positive. In addition, when the path difference is negative, these figures show that the frequency characteristics of measurement results and those of the predicted display a similar trend. This confirms that noise reduction by low barriers installed adjacent to the rails in the field tests does not agree with general predictions on insertion loss provided by low barriers quantitatively whereas they do qualitatively. The reason for the quantitative discrepancy between noise reduction measurements and predictions is as follows:

- Noise sources in the field tests with a diesel locomotive are located all over the bogie, whereas for the predictions, noise is assumed to be radiated from point sources.

- There were ground irregularities in the field tests.

- There were two bogies on the test car, whereas only a single point source was assumed for the prediction.

- It is estimated that the detailed frequency characteristics of noise reduction by low barriers installed adjacent to the rails are dependent on the contributions and the directivities of each noise generated from the under-body of vehicles.

\section{Prediction model for noise reduction by low bar- riers installed adjacent to the rails}

This section proposes a prediction model for noise reduction in elevated location through low barriers installed adjacent to the rails using the results of the field tests described in Section 3. The authors proposed a prediction model for noise generated from the under-body of vehicles [4]. In the model, there are two mirror sources to consider the reflections on the conventional sound barriers and the railway vehicle (Fig. 9). In addition, it is assumable that

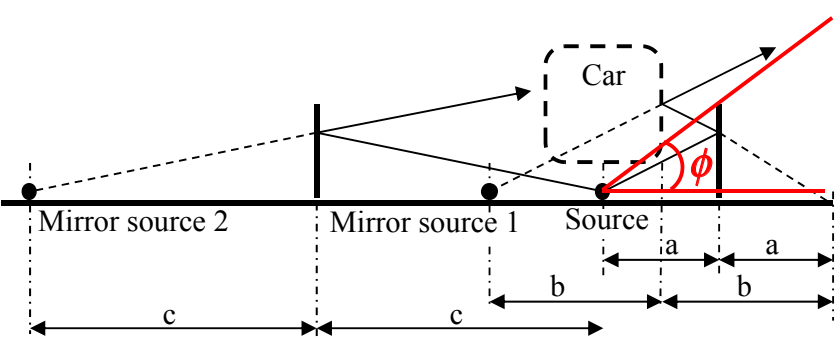

Fig. 9 Prediction model for the noise generated from the under-body of vehicles

the noise sources have directivity and the directivity function is given by the following:

$$
D(\phi)=0.1+0.9 \cos \phi
$$

where $\phi$ is the angle from the horizontal at source position (center of track, $0 \mathrm{~m}$ above R.L.) of the noise generated from the under-body of vehicles. In general, insertion loss of sound barrier is calculated using a Maekawa Chart [5] etc. However, in Section 3.2.2, noise reduction by low barriers installed adjacent to the rails in the field tests did not agree with the predicted insertion loss provided by low barriers based on the Maekawa Chart. In addition, if there are both conventional barriers and low barriers installed adjacent to the rails, it is very complicated to calculate the noise reduction of these noise barriers assuming there is double-barrier insertion loss. Then a new prediction model for noise generated from the under-body of vehicles where low barriers are installed adjacent to the rails is proposed by means of the vertical directivity of wayside noise according the low barrier installation conditions. Vertical directivity is derived by an empirical function of vertical directivity of the wayside noise observed during the field tests.

Figure 10 shows noise reduction achieved with low barriers installed adjacent to the rails under case 2 (height $0.9 \mathrm{~m}$, without absorbers) conditions during the field tests. Noise reduction is obtained by subtracting the measured noise level with barriers from the noise level without. In Fig. 10, the noise reduction achieved with low barriers in elevated positions where the noise level is not affected by ground reflection of sound equals out on radial lines extending from a point $0.5 \mathrm{~m}$ above the top of the barriers. Therefore, the noise reduction effect of low barriers can be approximated using an empirical function of an angle $\theta$ from the horizontal at that point. In the case of barriers as shown in Fig. 10, the noise reduction achieved with low barriers $\Delta L(\mathrm{~dB})$ can be approximated using the angle $\theta$ as follows

$$
\Delta L=0.0011 \theta^{2}-0.1745 \theta+6.6705 \quad\left(0^{\circ}<\theta<60^{\circ}\right)
$$

where $\theta$ is an angle from the horizontal at a point 0.5 $\mathrm{m}$ above the top of the barriers. The predicted noise reduction is shown in Fig. 11. Noise reduction with low barriers installed adjacent to the rails is predictable by adding noise reduction with low barriers $\Delta L$ to directivity of the noise sources $D(\phi)$. Verifications with conventional barriers or where the evaluated region is larger than the region in Fig. 10 and derivation of the empirical function for other barrier conditions remain problems. 


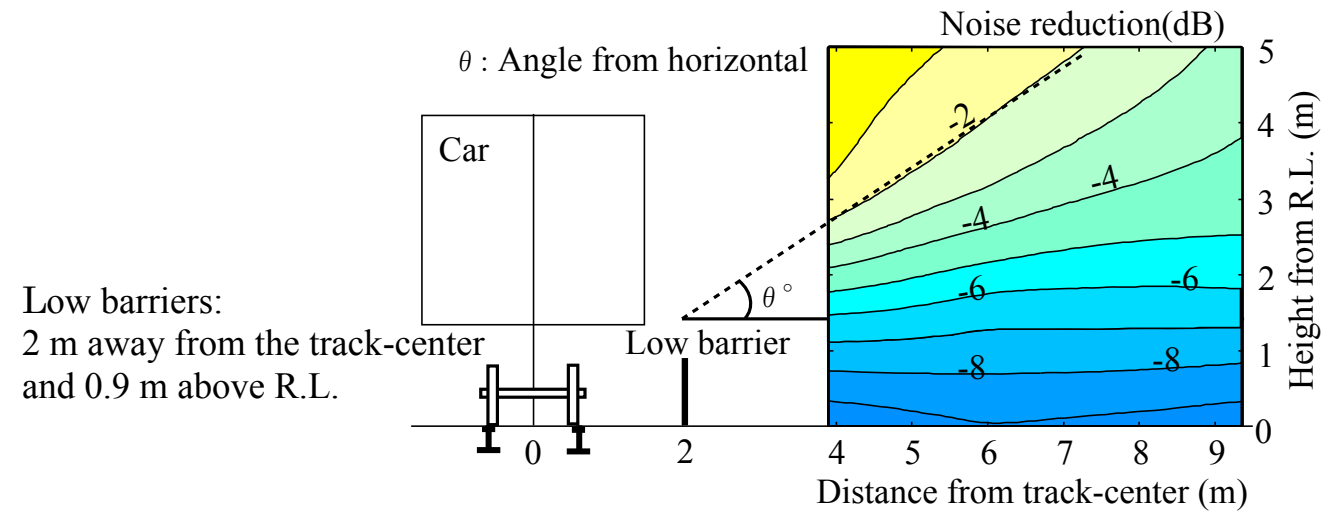

Fig. 10 Noise reduction of low barriers in Case 2 in the field tests

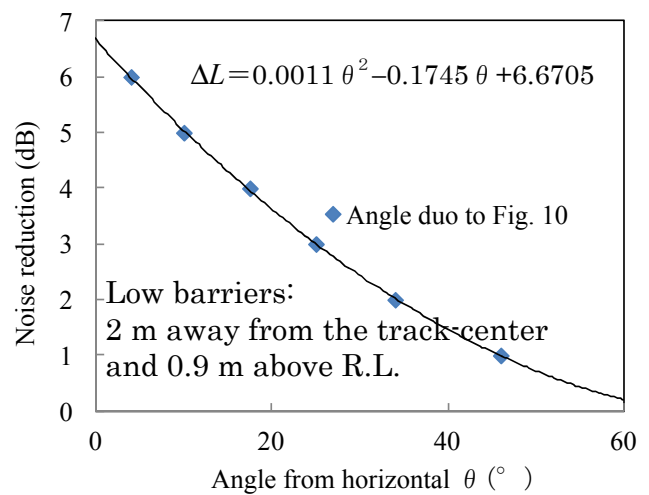

Fig. 11 An example for predicting noise reduction with low barriers by using $\theta$

\section{Conclusion}

Investigations were made into the noise reduction effect of low barriers installed adjacent to rails for preventing noise propagation to elevated positions through acoustic tests using scale models and field tests on existing railway. The parameters employed for these tests for the barriers were height, shape and presence of absorbers. In the acoustic tests, low barriers had a greater noise reduction effect when they were higher or the distance from the noise source grew shorter. Noise reduction effect of inverted $\mathrm{L}+\mathrm{T}$ type barriers was highest during tests where the barriers were same height and without absorbers. In field tests, noise reduction achieved with low barriers was less than in acoustic tests, and the frequency characteristics did not agree quantitatively with the predicted insertion loss using the method in the ASJ RTN-model, but agreed qualitatively. Furthermore, an empirical function was derived to represent the noise reduction of low barriers installed adjacent to the rails, and a prediction model for noise generated by the under-body of vehicles with low barriers installed adjacent to the rails was proposed by means of this empirical function.

\section{References}

[1] Ogata, Y., and Nagakura, K., "Noise reduction effect for wayside by noise barrier near track," proceedings of the 2010 Autumn Meeting of Institute of Noise Control Engineering of JAPAN, September 28-29, pp.131134, 2010 (in Japanese).

[2] Ogata, S., Fujuwara, K., Kitagawa, T., and Nagakura, K., "Experimental Examination with Elevated Structural Model Concerning Multiple Reflection of Noise Barrier in Noise Forecast of the Ordinary Railways," proceedings of the Inter-noise 2001, Hague, The Netherlands, August 27-30, 2001.

[3] Sakamoto, S., Fukushima, A. and Yamamoto, K., "Road traffic noise prediction model "ASJ RTN-Model 2008" proposed by the Acoustical Society of Japan-Part 3: Calculation model of sound propagation," presented at the Inter-noise 2009, Ottawa, Canada, August 23-26, 2009.

[4] Nagakura, K., Abe, Y., Kitagawa, T., Ogata, Y., Kozuma, Y. and Murata, K., "Study on Prediction Model for Railway Noise at High Places," proceedings of the International Congress on Sound and Vibration, Daejeon, Korea, July 6-10, 2008.

[5] Maekawa., J., "Noise reduction by screens," Applied Acoustics, Vol.1, pp.157-173, 1968. 